\title{
Editorial
}

\section{Announcement: The International System for Reporting Serous Fluid Cytopathology}

\author{
Ashish Chandra $^{\mathrm{a}}$ Barbara Crothers $^{\mathrm{b}}$ Daniel Kurtycz ${ }^{\mathrm{c}}$ Fernando Schmitt ${ }^{\mathrm{d}}$ e \\ a'Department of Cellular Pathology, Guy's \& St Thomas' NHS Foundation Trust, London, UK; ${ }^{b}$ Gynecologic, Breast, \\ and Cytopathology Services, Joint Pathology Center, Silver Spring, MD, USA; ' Department of Pathology and \\ Laboratory Medicine, University of Wisconsin School of Medicine and Public Health, Madison, WI, USA; ${ }^{\mathrm{d}}$ Medical \\ Faculty, Porto University, Porto, Portugal; ${ }^{e}$ Institute of Molecular Pathology and Immunology, Porto University, \\ Porto, Portugal
}

\section{Keywords}

Standardized reporting $\cdot$ International terminology $\cdot$ Serous fluids · Peritoneal washings

\begin{abstract}
Serous fluids are a common but important specimen type in a cytopathology laboratory. There is as yet no agreed standardized terminology to allow uniformity in reporting on these specimens. Given that serous fluids are a rich source of cytopathological as well as molecular information on a range of benign and often advanced malignant conditions, a unified approach to handling and reporting these specimens covering the pre-analytical, analytical and postanalytical stages seems timely. Representatives of the international cytology community have come together once again to develop an algorithmic diagnostic and management approach to the reporting of these samples.
\end{abstract}

(C) 2019 S. Karger AG, Basel

\section{Introduction}

Serous cavity effusions are a common presentation of a broad range of neoplastic and non-neoplastic medical conditions. Not surprisingly, they comprise a significant

\section{KARGER}

(c) 2019 S. Karger AG, Basel

E-Mail karger@karger.com

www.karger.com/acy workload in most cytopathology laboratories. In addition, samples of washings of the peritoneal cavity may accompany resected histopathology specimens from major surgical procedures on abdominal and pelvic organs. The clinical reason for sending these specimens (effusions and washings) is to confirm either the presence or absence of malignant cells as this would influence the prognosis and medical management of a patient.

\section{Existing Reporting Terminology Systems}

The Paris system for reporting urinary tract cytology [1] demonstrated that even common specimen types provide answers to important clinical questions and any efforts in standardizing terminology of reporting on these specimens would ultimately benefit patients. The system also provided an opportunity to revisit some fundamental issues such as adequacy criteria of urine samples in terms of volume and cellularity whilst aiming to reduce the burden of equivocal (atypical) diagnoses and reiterating the strength of urine cytology in the detection of high-grade urothelial carcinoma.

Established terminology systems, notably the Bethesda systems for reporting gynecological [2] and thyroid [3] cytology, have been successful in establishing an interna- 
tional language for communicating diagnostic results, and the more recent Milan [4] system for salivary glands and Papanicolaou systems for pancreaticobiliary [5] and pulmonary [6] cytology are also being adopted into clinical practice.

\section{How the Project Was Established}

A proposal was submitted to the International Academy of Cytology (IAC) Executive Board by the proponents outlining the clinical need for a terminology system for reporting serous fluid samples. Once approved, collaboration with the American Society for Cytopathology (ASC) was agreed, similar to that for the preceding Paris and Milan reporting systems. A team of coeditors and lead chapter authors were recommended by the IAC and the ASC, and, in turn, the chapter authors were nominated by the lead authors and editors. Besides histo/cytopathologists and cytotechnologists, invited authors included a respiratory physician and two oncologists.

\section{Rationale for the Reporting System}

Serous fluid cytology poses some important questions, the answers to which may help in offering further useful information to clinicians caring for patients. Whilst being a common specimen type, there is an acknowledged variability in processing and reporting on these cases.

Basic questions relating to the adequate volume and cell content of samples required to provide a reliable answer have only recently begun to be addressed. The amount of fluid sample to be sent to the cytology lab would be valuable guidance to clinicians. The cell components in serous fluids are inflammatory, mesothelial or malignant cells. It is, however, controversial whether the presence of normal or benign mesothelial cells should be a prerequisite for an adequate specimen.

Interpretation of mesothelial proliferations has long been an area of controversy. Any evidence-based guidance on the value of cytopathology reporting on these would, no doubt, be welcomed by the international cytology community.

Peritoneal washings are a unique type of serous fluid specimen and pose many diagnostic dilemmas. Whilst the presence of epithelial cells in a serous effusion in the pleural and pericardial cavities is regarded to be malignant, their presence in peritoneal washings opens up a number of possibilities. Overtly malignant epithelial cells may be recognized with ease, but bland or even convincingly benign cells with cilia may be encountered as a result of embryological, metaplastic and other benign conditions. These conditions need to be recognized and reported to avoid confusion with disseminated malignancy. Conversely, certain abdominal surgical procedures may result in iatrogenic introduction of obviously malignant cells in the specimen which may also be erroneously interpreted as metastasis or peritoneal tumor seeding. In some countries, intraoperative peritoneal washings in multiple cavities can predict a poor prognosis in gastric cancers [7].

Current reporting practices on serous fluids, in general, use a 5-tier terminology system of non-diagnostic, benign, atypical, suspicious, and malignant categories. The diagnostic criteria and the phraseology used does, however, vary, and any guidance on a standardized approach would be expected to improve the consistency and quality of reporting.

In line with current practice and following on in the footsteps of the preceding terminology systems, we propose the following diagnostic categories:

- Non-diagnostic (ND)

- Negative for malignancy (NFM)

- Atypia of undetermined significance (AUS)

- Suspicious for malignancy (SFM)

- Malignant (MAL) - primary and secondary

In practice, cases requiring ancillary testing are put into preliminary "holding" categories (atypia or suspicious) whilst awaiting further results that may move these into a more definitive benign or malignant category, thus minimizing the number of atypical and suspicious cases. However, diagnostic criteria for defining atypical and suspicious categories and their respective risk of malignancy have not been extensively studied.

\section{Online Survey of Current Practices}

These gaps in reporting practices merited a survey of existing practice, a review of the literature, and prospective studies to promote uniformity of reporting terminology across the world.

The editors recently conducted an online survey that has thrown light on the above issues and will help the authors in addressing the perceived problem areas. The results of this survey will be also published.

Work is well underway with the help of a consortium of authors on the book chapters which include proposed diagnostic categories and a special section on peritoneal 
washings, cytopreparatory techniques, ancillary techniques, and quality assurance as well as direction for future research.

\section{Standardized Reports and Clinical Management}

As with other terminology systems, illustrations and sample reports will be provided for all reporting categories together with clinical recommendations.

This project is a collaborative effort between the IAC and the ASC and calls upon participation of the cytology community to contribute to the development of a truly international system for reporting serous fluid cytopathology.

\section{Acknowledgment}

We acknowledge the ongoing efforts of the team of authors currently engaged in researching the evidence base and in writing the manuscript of the different chapters.

Non-Diagnostic: Mauro Saieg (MD, PhD, MIAC); Toshiaki Kamei (MD); Kaitlin Sundling (MD, PhD).

Pathogenesis Section: Stefan Pambuccian (MD); Miguel PerezMachado (MD, PhD).

Negative for Malignancy: Eva Wojcik (MD); Safa Alshaikh (MD); Claudia Lobo (MD); Bo Ping (MD).

Atypia of Undetermined Significance: Philippe Vielh (MD, $\mathrm{PhD}$ ); Rene Gerhard (MD); Marianne Lozano (MD, PhD); Voichita Suciu (MD).
Suspicious for Malignancy: Panagiota Mikou (MD); Marianne Engels (MD); Sinchita Roy-Chowdhuri (MD, PhD).

Malignant - Primary: Claire Michael (MD); Kenzo Hiroshima (MD, PhD); Anders Hjerpe (MD); Pam Michelow (MD); Binnur Onal (MD, FEBP, FIAC).

Malignant - Secondary: Ben Davidson (MD, PhD); Yurina Miki (MD); Laura Tabatabai (MD).

Peritoneal Washings: Christopher VandenBussche (MD, $\mathrm{PhD}$ ); Amanda Fader (MD); Amanda Jackson (MD); Zaibo Li (MDdu); Chengquan Zhao (MDdu).

Ancillary Testing: Lukas Bubendorf (MDch); Pinar Firat (MDr); Gilda Santos (MD, PhD, FRCPC, FIAC); Giancarlo Troncone (MD); Spasenija Savic Prince (MD).

Cytotechnical Aspects: Donna Russell (MEd CT/HT[ASCP]); Deepali Jain (MD).

Quality Assurance: Barbara Centeno (MD); Paul Cross (MD); Rosario Granados (MD); Marilin Rosa (MD).

Respiratory Physician Input: George Santis (MD).

Twitter and Social Media Group: Sachiko Minamiguchi (MD); Sinchita Roy-Chowdhuri (MD, PhD).

\section{Disclosure Statement}

The authors of this letter have no conflicts of interest to declare.

\section{Funding Sources}

No funding sources have been used for this collaboration.

\section{References}

1 Rosenthal DL, Wojcik EM, Kurtycz DF, editors. The Paris system for reporting urinary cytology. Springer; 2016.

2 Nayar R, Wilbur D, editors. The Bethesda system for reporting cervical cytology: definitions, criteria and explanatory notes. Springer; 2015.

3 Ali SZ, Cibas ES, editors. The Bethesda system for reporting thyroid cytopathology: definitions, criteria and explanatory notes. Springer; 2018. https://doi.org/10.1007/978-3-31960570-8.
4 Faquin WC, Rossi ED, Baloch Z, Barkan GA, Foschini M, Kurtycz DF, et al, editors. The Milan system for reporting salivary gland cytopathology. Springer; 2018. https://doi.org/ 10.1007/978-3-319-71285-7.

5 Pitman MB, Layfield LJ. The Papanicolaou Society of Cytopathology system for reporting pancreaticobiliary cytology: definitions, criteria and explanatory notes. Springer; 2015. https://doi.org/10.1007/978-3-31916589-9.
6 Layfield LJ, Baloch ZW, editors. The Papanicolaou Society of Cytopathology system for reporting respiratory cytology: definitions, criteria, explanatory notes and recommendations for ancillary testing. Springer; 2019. https://doi.org/10.1007/978-3-319-97235-0.

7 Homma Y, Ushida S, Yamada M, Kobayashi $\mathrm{H}$, Suzuki K. Positive peritoneal washing cytology in multiple cavities can predict poor prognosis of advanced gastric cancer patients. Ann Surg Oncol. 2010 Feb;17(2):455-60. 